\title{
Effect of coadsorbed water on deep oxidation mechanisms: temperature- programmed reactions of benzene and hydroxyl on the pt(111) surface
}

\author{
Anderson L. Marsh* and John L. Gland** \\ Department of Chemistry, University of Michigan, 930 N. University Avenue, Ann Arbor, MI 48109, USA
}

Received 8 November 2003; accepted 1 September 2004

\begin{abstract}
The deep oxidation of benzene by preadsorbed hydroxyl on the $\operatorname{Pt}(111)$ surface has been characterized using temperatureprogrammed reaction spectroscopy. A mechanism for benzene oxidation in the presence of coadsorbed water has been developed based on these experiments. Reaction-limited carbon dioxide and water are formed over the temperature range 330-530 K, indicating oxydehydrogenation and skeletal oxidation are occurring over this temperature range. Oxidation of benzene has been compared on the oxygen-covered $\operatorname{Pt}(111)$ surface with and without coadsorbed water. With preadsorbed hydroxyl, the yield of water at low-temperatures is increased, and the yield of carbon dioxide is increased. The temperature ranges for carbon dioxide and water formation above $300 \mathrm{~K}$ are increased by $30 \mathrm{~K}$ when water is coadsorbed with atomic oxygen to form hydroxyl. These results clearly suggest that hydroxyl enhances oxydehydrogenation below $300 \mathrm{~K}$, which results in the formation of different dehydrogenated intermediates with increased activation energy for oxidation during the reaction. Taken together these kinetic and mechanistic results provide a clear description of the reactivity of hydroxyl during benzene deep oxidation on the $\mathrm{Pt}(111)$ surface.
\end{abstract}

KEY WORDS: aromatics; catalysis; low index single crystal surfaces; oxidation; platinum; surface chemical reaction; thermal desorption spectroscopy; water.

\section{Introduction}

Transition-metal-catalyzed oxidations are used in many applications to efficiently produce desired chemical commodities and to eliminate unwanted pollutants [1]. More specifically, homogeneous and heterogeneous platinum catalysts have been shown to partially oxidize benzene to phenol [2,3]. Hydroxyl has been suggested as an important intermediate during these partial oxidations, as well as for the platinum-catalyzed complete oxidation of alkanes [4,5] and the oxidation of $\mathrm{CO}$ in the presence of water [6-8]. In the case of $\mathrm{CO}$ oxidation on the $\operatorname{Pt}(111)$ surface, water has been proposed either to reduce the activation energy for oxidation by stabilizing the transition state, or to react with atomic oxygen to form hydroxyl, which leads to a more preferred reaction mechanism [8]. Modern surface science has focused on exploring and understanding catalytic reactions to establish a molecular-level understanding of fundamental surface processes [9]. An understanding of the role of hydroxyl as an intermediate will improve the overall understanding of oxidation reaction mechanisms and kinetics. Because of the importance of hydroxyl as an intermediate, both partial and complete oxidations using hydroxyl remain an active area of current research.

The formation of hydroxyl from the reaction of water with the $(2 \times 2)$-O-Pt(111) surface has been shown to

\footnotetext{
* Present address: Department of Chemistry, University of California, Berkeley, Berkeley, CA 94720 , USA

** To whom correspondence should be addressed.

E-mail: gland@umich.edu
}

occur above $150 \mathrm{~K}$ [10]. The following stoichiometric reaction has been proposed for hydroxyl formation on $\operatorname{Pt}(111)[11,12]$ :

$$
2 \mathrm{H}_{2} \mathrm{O}_{\mathrm{a}}+\mathrm{O}_{\mathrm{a}} \rightarrow 3 \mathrm{OH}_{\mathrm{a}}+\mathrm{H}_{\mathrm{a}}
$$

The structure and bonding of $\mathrm{OH}$ formed through this reaction on the $\mathrm{Pt}(111)$ surface has been characterized by several surface science techniques [10,12-15]. Based on these results, hydroxyl produced by the above reaction is suggested to form a $(\sqrt{3} \times \sqrt{3}) \mathrm{R} 30^{\circ}$ structure composed of two O-containing groups in on-top positions $[12,13]$. Despite the stoichiometry of the above reaction, the saturation coverage for hydroxyl is $0.67 \mathrm{ML}$ [12]. Theoretical calculations have shown that hydroxyl has a weaker covalent bond to $\mathrm{Pt}(111)$ compared to that of atomic oxygen, which should result in increased chemical reactivity [14]. Several surface reactions involving hydroxyl have been investigated on metal single crystal surfaces other than the $\operatorname{Pt}(111)$ surface $[16,17]$. Hydroxyl formation by coadsorption of water with atomic oxygen was shown to inhibit propylene combustion on the $\mathrm{Ag}(110)$ surface and to decrease the propylene desorption temperature relative to that for oxygen-covered $\operatorname{Ag}(110)$ [16]. In another study, the molecular chemisorption of ammonia was inhibited on the hydroxyl-covered $\mathrm{Ni}(110)$ surface, while hydrogen-bonding interactions of ammonia with hydroxyl were stronger compared to those between adsorbed ammonia molecules [17]. These results clearly indicate the range of the reactivity and interactions of hydroxyl on metal surfaces. 
The interactions of benzene with the $\operatorname{Pt}(111)$ surface have been thoroughly studied using a variety of surface science techniques [18-26]. Based on these characterizations, benzene pi-bonds to $\mathrm{Pt}(111)$ with the ring parallel to the plane of the surface $[18,20,22]$. The chemisorbed benzene layer consists of two states, which are desorbed with activation energies of $82-88 \mathrm{~kJ} / \mathrm{mol}$ and $117-$ $129 \mathrm{~kJ} / \mathrm{mol}$ over the $280-520 \mathrm{~K}$ temperature range $[19,21,24]$. More recently DFT calculations have determined the most preferred site for benzene adsorption on the $\operatorname{Pt}(111)$ surface is the bridge site, which is occupied first during adsorption, while at higher coverages a threefold hollow site is occupied [26]. Investigations of benzene oxidation on the $\mathrm{Pt}(111)$ surface have been limited, however. We have previously reported on the deep oxidation of benzene on the $\mathrm{Pt}(111)$ surface over a range of benzene and oxygen coverages [27,28]. Benzene is oxidized by coadsorbed oxygen to produce carbon dioxide and water, which both desorb in reactionlimited peaks over the temperature range $300-500 \mathrm{~K}$. Carbon-hydrogen and carbon-carbon bond activation are clearly rate-limiting steps for carbon dioxide and water formation. Oxidation of benzene adsorbed in bridge sites is preferred, suggesting enhanced reactivity in the bridge-bonded configuration. In pressures of flowing oxygen, benzene catalytic oxidation proceeds through four strongly adsorbed surface intermediates with increasing temperature.

In this letter, the characterization of the deep oxidation of benzene by preadsorbed hydroxyl on the $\mathrm{Pt}(111)$ surface using temperature-programmed reaction spectroscopy (TPRS) is described. Carbon dioxide and water are formed and are desorbed in reaction-limited peaks over the $330-530 \mathrm{~K}$ temperature range. When the oxidations of benzene with and without coadsorbed water on the oxygen-covered $\mathrm{Pt}(111)$ surface are compared, the yield of water at low temperatures is increased and the yield of carbon dioxide is increased. Additionally, the temperature range for carbon dioxide and water formation and desorption above $300 \mathrm{~K}$ is increased by $30 \mathrm{~K}$. These results suggest the formation of a surface intermediate, through a low-temperature oxydehydrogenation channel, with higher activation energy for oxidation, yet higher reaction yields. These findings provide a clear description of the effect of coadsorbed water on and the reactivity of hydroxyl during benzene deep oxidation on the $\mathrm{Pt}(111)$ surface.

\section{Experimental}

These experiments were conducted on the Ann Arbor ultra-high vacuum chamber at the University of Michigan, which has been described in detail previously [27]. The $\mathrm{Pt}(111)$ crystal was mounted on a ceramic plug, which was inserted into an L-shaped liquid nitrogen feedthrough attached to a manipulator capable of $x-y-z$ motion and $360^{\circ}$ rotation. The temperature was monitored by a Type $\mathrm{K}$ thermocouple spot-welded to the back of the crystal. The crystal surface was initially cleaned by repeated cycles of $\mathrm{Ar}^{+}$sputtering, hightemperature annealing, heating in background pressures of oxygen, and high-temperature annealing. Surface cleanliness was verified by Auger electron spectroscopy. In between experiments the crystal surface was cleaned by heating in background pressures of oxygen, then annealing briefly at $1000 \mathrm{~K}$. Afterwards, surface cleanliness was verified by oxygen temperature-programmed desorption.

The TPRS experiments were performed using a UTI $100 \mathrm{C}$ mass spectrometer interfaced with a PC. A heating rate of $5 \mathrm{~K} / \mathrm{s}$ was used for these experiments. To limit the contribution from the tantalum wires, the crystal was placed $2 \mathrm{~mm}$ in front of a collimator on the mass spectrometer. Oxygen (Air Products, research grade) was used without further purification. Initially, the benzene (Baker Analyzed) and deionized water were purified by freeze-pump-thawing several times, and the purity was checked by mass spectrometry. After that, the liquids were freeze-pump-thawed at the start of each set of experiments. The reactive gases were directly dosed using stainless steel capillaries and variable leak valves. All gas exposures were performed with the crystal temperature below $100 \mathrm{~K}$. Benzene exposures are reported in Langmuirs (L) and are uncorrected for the ionization gauge sensitivity or the directed dosing configuration. Atomic oxygen coverages were prepared by heating coverages of molecular oxygen to $150 \mathrm{~K}$ [29]. Hydroxyl coverages were prepared by heating a saturated coverage of water adsorbed on an atomic oxygencovered surface to $190 \mathrm{~K}[10,12]$. Atomic oxygen and hydroxyl coverages are reported in monolayers (ML), which are referenced to the $\mathrm{Pt}(111)$ surface where $1 \mathrm{ML}$ corresponds to $1.5 \times 10^{15} \mathrm{Pt}$ atoms $/ \mathrm{cm}^{2}$.

\section{Results}

The TPR spectra for the reaction of a saturated coverage $(0.2 \mathrm{~L}$ exposure) of benzene with a preadsorbed saturated coverage ( $0.67 \mathrm{ML})$ of hydroxyl are displayed in figure 1. With hydroxyl preadsorbed, benzene is desorbed in one peak at $160 \mathrm{~K}$. The major reaction products desorbed from the surface are carbon dioxide (mass 44 spectrum) and water (mass 18 spectrum). No significant concentrations of carbon monoxide were detected. The initial water desorption peak at $210 \mathrm{~K}$ results primarily from water produced by the disproportionation of hydroxyl to produce atomic oxygen and water. The major oxidation products, $\mathrm{CO}_{2}$ and $\mathrm{H}_{2} \mathrm{O}$, are desorbed between 330 and $530 \mathrm{~K}$. No peaks are present in the mass 32 spectrum, indicating all of the oxygen reacts to form carbon dioxide and water. Once the oxygen has been consumed by reaction, the 


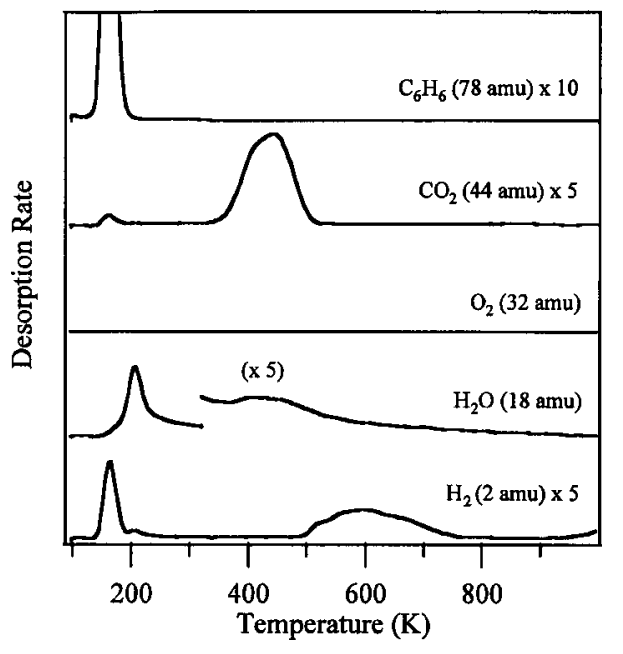

Figure 1. TPR spectra for the reaction of a $0.2 \mathrm{~L}$ postexposure of benzene with $0.67 \mathrm{ML}$ of preadsorbed hydroxyl on the $\mathrm{Pt}(111)$ surface.

remaining benzene is dehydrogenated to produce adsorbed carbon, and hydrogen, which is desorbed in two peaks over the temperature range $500-800 \mathrm{~K}$. Coverage effects on this oxidation reaction were studied by varying the concentration of preadsorbed hydroxyl or benzene.

The reaction of increasing preadsorbed hydroxyl coverages $(0.35,0.51$, and $0.67 \mathrm{ML})$ with saturated coverages $(0.2 \mathrm{~L}$ exposures) of benzene is seen in the TPR spectra in figure 2. The intensity of the benzene desorption peak at $160 \mathrm{~K}$ (mass 78 panel) is increased by $40 \%$ as the hydroxyl coverage is increased from 0.35 to $0.67 \mathrm{ML}$. As shown in the mass 18 panel, the $210 \mathrm{~K}$ desorption peak for water increases in intensity with increasing hydroxyl coverage. The broad desorption peak for water above $300 \mathrm{~K}$ is also increased in intensity as the hydroxyl coverage is increased. (The strong overlap of these two peaks prevents a quantitative estimate of the percentage increase in intensity with increasing hydroxyl coverage.) In addition, the temperature of this desorption peak is increased as the hydroxyl coverage is increased. The carbon dioxide desorption peak, as observed in the panel for mass 44 , is increased in intensity by a factor of 3 as the hydroxyl coverage is increased from 0.35 to $0.67 \mathrm{ML}$. The temperature of this desorption peak is also increased by $15 \mathrm{~K}$ as the hydroxyl coverage is increased. However, the onset temperature for the carbon dioxide desorption peak does not change with increasing hydroxyl coverage. As seen in the panel for mass 2, intensities of desorption peaks for hydrogen are decreased with increasing hydroxyl coverage. Increased hydroxyl surface concentration increases the concentration of both $\mathrm{CO}_{2}$ and $\mathrm{H}_{2} \mathrm{O}$ formed and desorbed during oxidation, as well as the product desorption peak temperatures.

The transition from excess hydroxyl to excess benzene, where saturated coverages $(0.67 \mathrm{ML})$ of hydroxyl

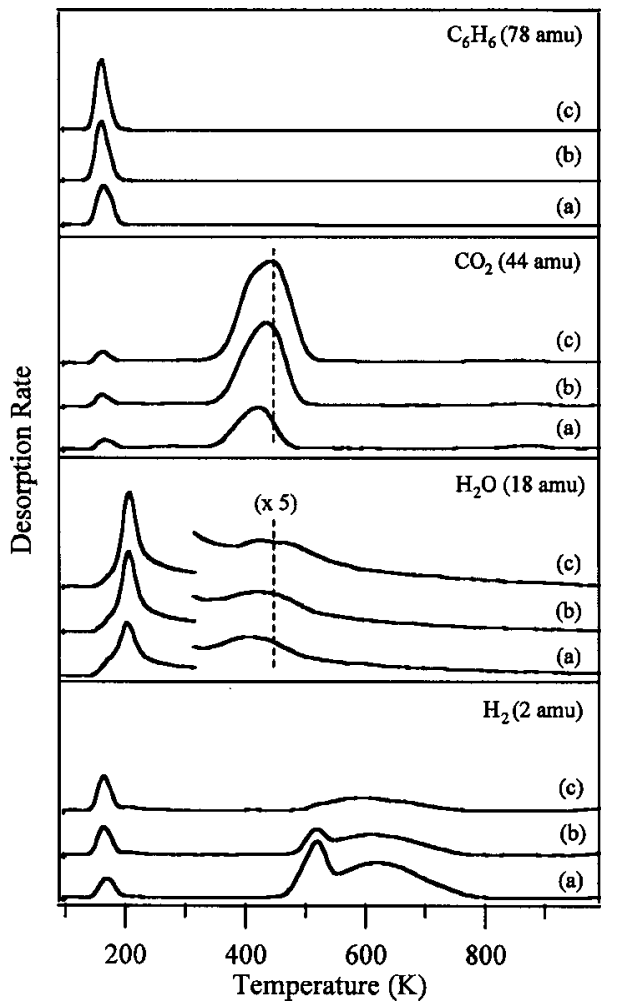

Figure 2. TPR spectra for the reaction of $0.2 \mathrm{~L}$ postexposures of benzene with increasing coverages of preadsorbed hydroxyl. The hydroxyl coverages are (a) $0.35 \mathrm{ML}$, (b) $0.51 \mathrm{ML}$, and (c) $0.67 \mathrm{ML}$.

were exposed to different doses $(0.005$ and $0.2 \mathrm{~L}$ exposures) of benzene, is shown in the TPR spectra in figure 3. As seen in the mass 2 spectra, hydrogen desorption peaks at 520 and $635 \mathrm{~K}$ are present only for excess benzene. No hydrogen is desorbed when hydroxyl is in excess. The $210 \mathrm{~K}$ water desorption peak, seen in both mass 18 spectra, does not change significantly. The $440 \mathrm{~K}$ water desorption peak (mass 18

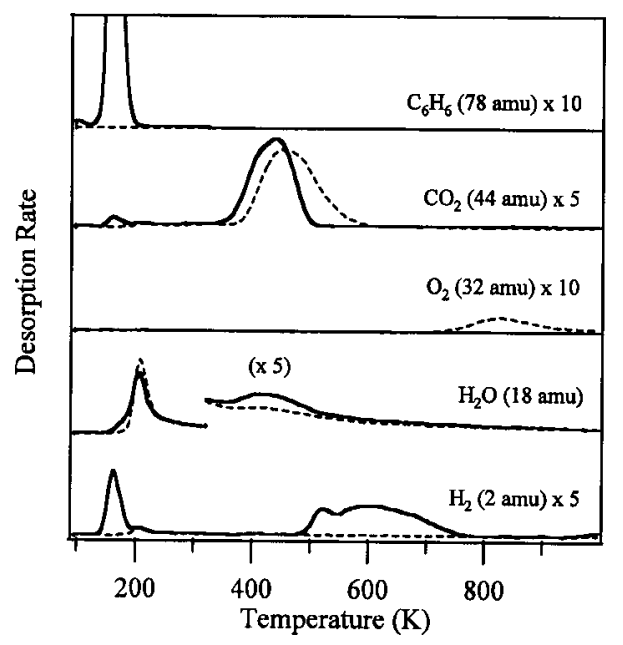

Figure 3. TPR spectra for the reaction of benzene with preadsorbed hydroxyl on the $\operatorname{Pt}(111)$ surface for the conditions of excess benzene (-) and excess hydroxyl (- - -). 
spectra) is present in the spectrum for the condition of excess benzene, but is not discernable in the spectrum for the condition of excess hydroxyl. The carbon dioxide desorption peak, seen in the spectra for mass 44, decreases in temperature by $20 \mathrm{~K}$ for the larger benzene exposure. Remaining atomic oxygen recombines and desorbs above $800 \mathrm{~K}$ for the smaller benzene coverage, as observed in the mass 32 spectrum corresponding to excess hydroxyl. As seen in the spectra for mass 78, no benzene is desorbed when hydroxyl is in excess on the surface. Excess benzene is desorbed in a sharp peak located at $160 \mathrm{~K}$. In addition to these experiments involving different surface coverages of benzene and hydroxyl, the reactivity of benzene on the hydroxylcovered Pt(111) surface has been compared to the reactivity of benzene on the clean $\operatorname{Pt}(111)$ surface and the oxygen-covered $\mathrm{Pt}(111)$ surface.

The reactions of $0.2 \mathrm{~L}$ exposures of benzene on the clean $\operatorname{Pt}(111)$ surface, the $\operatorname{Pt}(111)$ surface covered with $0.25 \mathrm{ML}$ of atomic oxygen, and the $\mathrm{Pt}(111)$ surface covered with $0.67 \mathrm{ML}$ of hydroxyl are shown in figure 4. As seen in the mass 78 panel, chemisorbed benzene desorbs in two peaks, one at $320 \mathrm{~K}$ and another at $425 \mathrm{~K}$, from the $\mathrm{Pt}(111)$ surface with no coadsorbates. When oxygen is preadsorbed, chemisorbed benzene desorbs at $320 \mathrm{~K}$, and the peak at $425 \mathrm{~K}$ is almost completely suppressed. No chemisorbed benzene desorbs when hydroxyl is preadsorbed. Carbon dioxide and water desorb over the temperature range $300-500 \mathrm{~K}$ when oxygen is preadsorbed on the surface. The temperature range of the carbon dioxide desorption peak, shown in the mass 44 panel, is increased by $30 \mathrm{~K}$ when water is coadsorbed with oxygen to form hydroxyl. The intensity of the peak is also increased by $15 \%$ when hydroxyl is preadsorbed instead of atomic oxygen. The mass 18 panel shows that the temperature range for water desorption above $300 \mathrm{~K}$ is increased by $30 \mathrm{~K}$, as well as the intensity of the desorption peak, when hydroxyl is preadsorbed instead of atomic oxygen.
The intensity of the low-temperature water desorption peak at $210 \mathrm{~K}$ is increased significantly for preadsorbed hydroxyl compared to that for preadsorbed atomic oxygen. The yield of and desorption peak temperatures for the products $\left(\mathrm{CO}_{2}\right.$ and $\left.\mathrm{H}_{2} \mathrm{O}\right)$ of benzene deep oxidation are increased by coadsorption of water with oxygen to form hydroxyl. Taken together these temperature-programmed results provide a strong basis for understanding benzene interactions and reactions with hydroxyl on the $\operatorname{Pt}(111)$ surface.

\section{Discussion}

Based on results for these temperature-programmed oxidation experiments, the adsorption and reactions of benzene on the $\operatorname{Pt}(111)$ surface are clearly different with preadsorbed hydroxyl relative to those with preadsorbed atomic oxygen. When hydroxyl is preadsorbed, no benzene desorbs from the surface above $200 \mathrm{~K}$, clearly indicating the formation of a strongly bound benzenederived surface intermediate. The increase in yields of reaction products (carbon dioxide and water) suggests an intermediate with enhanced reactivity. In addition, carbon dioxide and water are desorbed in reactionlimited peaks over the temperature range 330-530 K. This temperature range is $30 \mathrm{~K}$ higher than the temperature range for product formation during the reaction of benzene and atomic oxygen, indicating the formation of an intermediate with increased activation energy for oxidation. Finally, a mechanism has been developed for the deep oxidation of benzene in the presence of coadsorbed water on the Pt(111) surface.

The preadsorption of hydroxyl on Pt(111) clearly alters the adsorption and bonding of benzene on the surface. The benzene multilayer desorption peak temperature is decreased compared to that for benzene adsorbed on the clean Pt(111) surface and the oxygencovered Pt(111) surface. Benzene has been suggested to

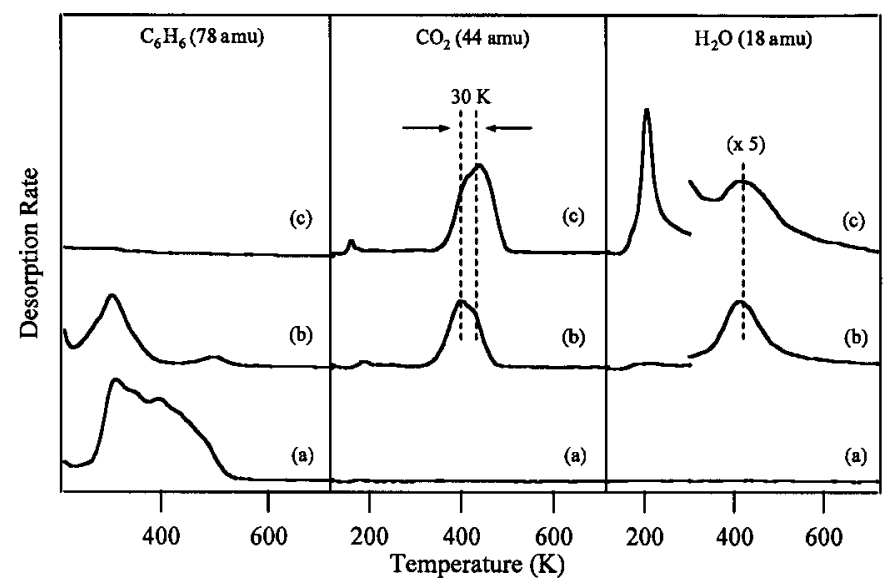

Figure 4. TPR spectra for the reaction of benzene on (a) $\mathrm{Pt}(111)$, (b) $\mathrm{Pt}(111)$ with $0.25 \mathrm{ML}$ preadsorbed atomic oxygen, and (c) Pt(111) with $0.67 \mathrm{ML}$ preadsorbed hydroxyl. 
adsorb on top of oxygen adsorbed in threefold hollow sites based on previous TPRS results [27]. Since the saturation coverage for hydroxyl $(0.67 \mathrm{ML})$ is greater than the saturation coverage for atomic oxygen (0.25 ML) [12], it is likely that a fraction of benzene is physisorbed on top of the hydroxyl chemisorbed on the $\operatorname{Pt}(111)$ surface. In the case of the hydroxylated surface, the pi system of benzene would be expected to interact with the hydrogen in the hydroxyl on the surface. This interaction has been suggested to occur between benzene and hydroxyl groups present on alumina [30] and titania surfaces [31]. Theoretical calculations have shown that hydrogen-bonding interactions are predominant in benzene-water systems [32]. During the reaction of hydroxyl to form atomic oxygen and water, no benzene desorbs above $200 \mathrm{~K}$, which clearly indicates that benzene reacts to form a strongly adsorbed intermediate. The electron donating capability of the platinum surface is increased due to the weaker covalent bond with hydroxyl as compared to that with atomic oxygen [14]. Benzene and the benzene-derived intermediate may therefore be more strongly adsorbed to the hydroxyl-covered platinum surface because of the stronger back donation of the platinum surface. This stronger bonding clearly leads to an enhanced reactivity during oxidation of benzene and benzene-derived intermediates on the $\operatorname{Pt}(111)$ surface. The enhanced yield of oxidation products from this intermediate is clearly seen in figure 4, where desorption of carbon dioxide and water are compared for three different Pt(111) surfaces. Both the temperature of the carbon dioxide reaction peak and the carbon dioxide yield are increased. The low-temperature oxidation of carbon monoxide on the $\operatorname{Pt}(111)$ surface has been shown to be enhanced by small amounts of coadsorbed water [6]. For this case, the authors suggest that the addition of water creates hydroxyl on the platinum surface, which inhibits the self-poisoning of the reaction by carbon monoxide.

As discussed previously and shown in figure 1, reaction-limited peaks for both carbon dioxide and water are observed from 330 to $530 \mathrm{~K}$, which clearly indicates that oxydehydrogenation and skeletal oxidation both occur during this temperature range. Similar reactivity was observed on the $\operatorname{Pt}(111)$ surface for the oxidation of benzene with preadsorbed oxygen [27]. However, as observed in figure 4 , the temperature range and reaction peak temperatures for both water and carbon dioxide formation during the reaction of benzene with preadsorbed hydroxyl are increased by $30 \mathrm{~K}$ compared to those for benzene reacting with preadsorbed atomic oxygen. This temperature increase suggests the formation of a strongly bound surface intermediate with increased activation energy for oxidation. Not only is the temperature range for carbon dioxide formation and desorption increased, but temperature of the desorption peak is also increased with increasing hydroxyl coverage. No increase was observed during the oxidation of benzene by increasing coverages of coadsorbed oxygen on the $\operatorname{Pt}(111)$ surface [27], which also indicates the formation of a different surface intermediate. The intermediate is likely formed by lowtemperature oxydehydrogenation, as evidenced by the increase in the yield of water below $300 \mathrm{~K}$. At low temperatures during benzene oxidation by coadsorbed oxygen, $\eta^{6}$-benzene adsorbed on bridge sites first forms the $\mathrm{C}_{6} \mathrm{H}_{6}$ 1,4-di- $\sigma$-2,5-cyclohexadiene intermediate through rearrangement of the aromatic system, then the $\mathrm{C}_{6} \mathrm{H}_{5}$ 1,1,4-tri- $\sigma$-2,5-cyclohexadiene intermediate through oxydehydrogenation [28]. As the temperature is increased the $\mathrm{C}_{6} \mathrm{H}_{5} \mathrm{O} \eta^{5}$-cyclohexadienone intermediate is formed and oxidized. The intermediate formed at low temperatures in the presence of coadsorbed hydroxyl likely has a stoichiometry of $\mathrm{C}_{6} \mathrm{H}_{5}$, based on the qualitative similarities of the TPR spectra. However, the stronger bonding of benzene to the platinum surface suggests the aromatic system is stabilized. This stabilization of the aromatic system may lead to the formation of a strongly bound oxygenated intermediate at higher temperatures that is aromatic. The presence of water during carbon monoxide oxidation has been suggested to alter the reaction mechanism through the formation of different surface intermediates [8]. As shown in this work, coadsorption of water clearly alters the mechanism through the formation of a different surface intermediate.

The mechanism developed for the deep oxidation of benzene in the presence of coadsorbed water on the $\operatorname{Pt}(111)$ surface is presented in figure 5. In the initial step of the mechanism, a fraction of the benzene desorbs by $200 \mathrm{~K}$, while the benzene remaining on the surface undergoes reaction. The first water desorption peak is located at $210 \mathrm{~K}$. During this step, a portion of hydroxyl disproportionates to produce atomic oxygen and a fraction of the desorbing water, while the remainder reacts with benzene to form water, which desorbs, and
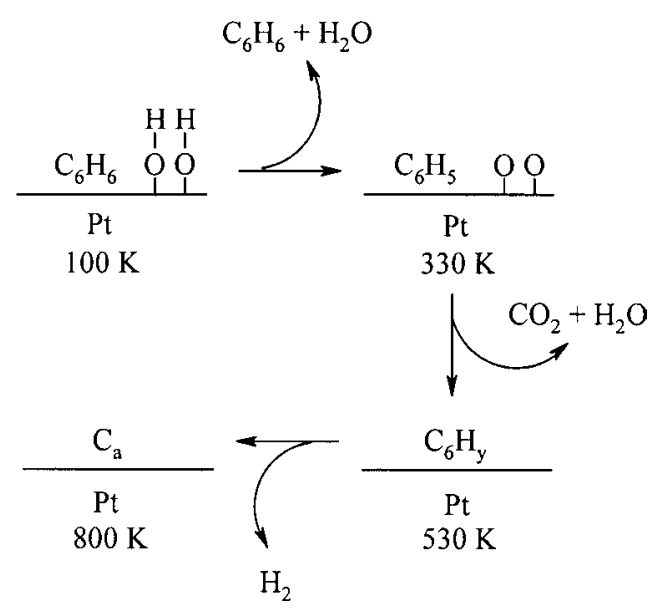

Figure 5. Mechanism for the deep oxidation of benzene with preadsorbed hydroxyl on the $\operatorname{Pt}(111)$ surface. 
the dehydrogenated intermediate. Over the temperature range $330-530 \mathrm{~K}$ the benzene-derived intermediate is oxidized to form $\mathrm{CO}_{2}$ and $\mathrm{H}_{2} \mathrm{O}$. As soon as all of the surface oxygen is consumed by reaction, the remaining benzene-derived organic species dehydrogenate to form organic fragments, which remain on the surface. These dehydrogenated organic fragments evolve hydrogen and are completely dehydrogenated by $800 \mathrm{~K}$. When hydro$\mathrm{xyl}$ is in excess, all of the surface carbon and hydrogen react to form $\mathrm{CO}_{2}$ and $\mathrm{H}_{2} \mathrm{O}$, and any remaining atomic oxygen recombines and desorbs above $700 \mathrm{~K}$.

\section{Conclusions}

TPRS has been used to characterize the effect of coadsorbed water on the mechanism of benzene deep oxidation on the $\mathrm{Pt}(111)$ surface. Benzene desorbs below $200 \mathrm{~K}$, indicating weak interactions between physisorbed benzene and the hydroxyl layer. Reaction-limited carbon dioxide and water are formed over the temperature range $330-530 \mathrm{~K}$, indicating oxydehydrogenation and skeletal oxidation are occurring over this temperature range. Temperature ranges for carbon dioxide and water desorption are increased by $30 \mathrm{~K}$ when hydroxyl is preadsorbed instead of atomic oxygen. Direct comparison of TPRS intensities indicates hydroxyl, compared to atomic oxygen, increases the yield of benzene oxidation products. These results suggest an intermediate, formed at low temperatures through oxydehydrogenation by preadsorbed hydroxyl, with higher activation energy for oxidation and higher reaction yields. Further spectroscopic experiments will provide detailed information on the structure and stoichiometry of benzene-derived intermediates formed during deep oxidation in the presence of coadsorbed water.

\section{References}

[1] J.M. Thomas and W.J. Thomas, Principles and Practice of Heterogeneous Catalysis (VCH Publishers, Inc., New York, 1997).

[2] K. Sakai and K. Matsumoto, J. Mol. Catal. 67 (1991) 7.
[3] T. Miyake, M. Hamada, Y. Sasaki and M. Oguri, Appl. Catal. A 131 (1995) 33.

[4] C.M. Marks and L.D. Schmidt, Chem. Phys. Lett. 178 (1991) 358.

[5] C.E. Mooney, L.C. Anderson and J.H. Lunsford, J. Phys. Chem. 95 (1991) 6070.

[6] J. Bergeld, B. Kasemo and D.V. Chakarov, Surf. Sci. 495 (2001) L815.

[7] A. Manasilp and E. Gulari, Appl. Catal. B 37 (2002) 17.

[8] X.-Q. Gong, P. Hu and R. Raval, J. Chem. Phys. 119 (2003) 6324.

[9] G.A. Somorjai, Introduction to Surface Chemistry and Catalysis (John Wiley \& Sons, Inc., New York, 1994).

[10] G.B. Fisher and B.A. Sexton, Phys. Rev. Lett. 44 (1980) 683.

[11] J.R. Creighton and J.M. White, Surf. Sci. 122 (1982) L648.

[12] K. Bedürftig, S. Völkening, Y. Wang, J. Wintterlin, K. Jacobi and G. Ertl, J. Chem. Phys. 111 (1999) 11147.

[13] A.P. Setsonen, Y. Zhu, K. Bedürftig and H. Over, J. Am. Chem. Soc. 123 (2001) 7347.

[14] M. Chen, S.P. Bates, R.A. van Santen and C.M. Friend, J. Phys. Chem. B 101 (1997) 10051.

[15] M. Nagasaka, I. Nakai, H. Kondoh, T. Ohta and V. Carravetta, Chem. Phys. Lett. 375 (2003) 419.

[16] J.T. Ranney, S.R. Bare and J.L. Gland, Catal. Lett. 48 (1997) 25.

[17] H. Guo and F. Zaera, Surf. Sci. 524 (2003) 1.

[18] S. Lehwald, H. Ibach and J.E. Demuth, Surf. Sci. 78 (1978) 577.

[19] M.-C. Tsai and E.L. Muetterties, J. Am. Chem. Soc. 104 (1982) 2534.

[20] J.A. Horsley, J. Stöhr, A.P. Hitchcock, D.C. Newbury, A.L. Johnson and F. Sette, J. Chem. Phys. 83 (1985) 6099.

[21] J.M. Campbell, S. Seimanides and C.T. Campbell, J. Phys. Chem. 93 (1989) 815.

[22] A. Wander, G. Held, R.Q. Hwang, G.S. Blackman, M.L. Xu, P. de Andres, M.A. Van Hove and G.A. Somorjai, Surf. Sci. 249 (1991) 21.

[23] P.S. Weiss and D.M. Eigler, Phys. Rev. Lett. 71 (1993) 3139.

[24] C. Xu, Y.-L. Tsai and B.E. Koel, J. Phys. Chem. 98 (1994) 585.

[25] S. Haq and D.A. King, J. Phys. Chem. 100 (1996) 16957.

[26] M. Saeys, M.-F. Reyniers, G.B. Marin and M. Neurock, J. Phys. Chem. B 106 (2002) 7489.

[27] A.L. Marsh and J.L. Gland, Surf. Sci. 536 (2003) 145.

[28] A.L. Marsh, D.J. Burnett, D.A. Fischer and J.L. Gland, J. Phys. Chem. B 107 (2003) 12472.

[29] J.L. Gland, B.A. Sexton and G.B. Fisher, Surf. Sci. 95 (1980) 587.

[30] D.M. Haaland, Surf. Sci. 102 (1981) 405.

[31] Y. Suda, Langmuir 4 (1988) 147.

[32] S. Tsuzuki, K. Honda, T. Uchimaru, M. Mikami and K. Tanabe, J. Am. Chem. Soc. 122 (2000) 11450. 